https://doi.org/10.30910/turkjans.668140

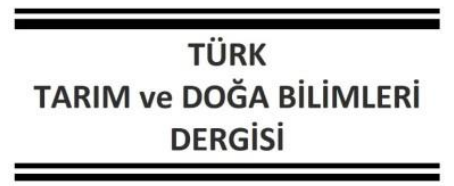

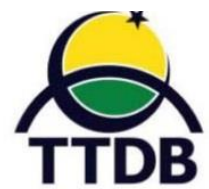

www.dergipark.gov.tr/turkjans

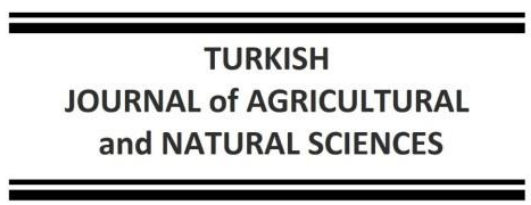

Araştırma Makalesi

\title{
Sultani Çekirdeksiz Üzüm Çeşidinde Farklı GA3 Uygulamalarının Üzüm Verim ve Kalitesine Etkilerinin Belirlenmesi
}

\author{
Özkan TAVŞAN ${ }^{1}$, Alper DARDENIZ $^{1 *}$, Esra ŞAHIN ${ }^{1}$ \\ ${ }^{1}$ ÇOMÜ Ziraat Fakültesi, Bahçe Bitkileri Bölümü. 17100/Çanakkale \\ *Sorumlu yazar: adardeniz@comu.edu.tr
}

\section{Geliş Tarihi: 31.12.2019 Düzeltme Geliş Tarihi: 13.10.2020 Kabul Tarihi: 14.10.2020}

\section{Öz}

Bu araştırma, Denizli ilinin Honaz ilçesindeki 41B Amerikan asma anacı üzerine aşılı Sultani Çekirdeksiz üzüm çeşidi bağlarında, 2018 yılında yürütülmüştür. Araştırmada, Sultani Çekirdeksiz üzüm çeşidinde farklı GA3 uygulamalarının (kontrol, 15-60 ppm GA3, 20-80 ppm GA3, 80-100 ppm GA3 + 20 ppm Forchlorfenuron) üzüm verim ve kalitesine etkilerinin belirlenmesi amaçlanmıştır. Elde edilen bulgulara göre; Sultani Çekirdeksiz üzüm çeşidinde yapılan farklı uygulamalar, kontrole kıyasla üzüm verim ve kalitesinde önemli artışlara neden olmuştur. Ortalama verim $(49.32 \mathrm{~kg} /$ omca), salkım eni $(9.59 \mathrm{~cm})$, salkım boyu $(31.97 \mathrm{~cm})$, salkım ağırlığı (1804.3 g/salkım), salkım sıklığı (8.57), tane eni $(15.79 \mathrm{~mm})$, tane boyu $(22.71 \mathrm{~mm})$ ve tane ağırlığı (3.50 g) parametrelerinde en yüksek değerler, üçüncü uygulama olarak belirlenen 80-100 ppm GA3+20 ppm Forchlorfenuron uygulamasından elde edilmiştir.

Anahtar Kelimeler: GA3, Forchlorfenuron, Sultani çekirdeksiz, Üzüm verimi, Üzüm kalitesi

\section{The Determination of Effects of Different GA3 Application on Grape Yield and Quality in Sultani Cekirdeksiz Grape Variety}

\begin{abstract}
This research was carried out using vineyards of Sultani Cekirdeksiz grape variety grafted on 41B American grapevine rootstock in Honaz district of Denizli province in 2018. This aim of this research was to determine the effects of different GA3 applications (control, 15-60 ppm GA3, 20-80 ppm GA3, 80-100 ppm $\mathrm{GA} 3+20$ ppm Forchlorfenuron) on grape yield and quality in Sultani Cekirdeksiz grape variety. According to the findings of the research, the applications in Sultani Cekirdeksiz grape variety were caused significant increases in grape yield and quality compared to control. The highest values of average yield (49.32 kg/vinestock), cluster width $(9.59 \mathrm{~cm})$, cluster length $(31.97 \mathrm{~cm})$, cluster weight $(1804.3 \mathrm{~g} /$ cluster $)$, cluster compactness $(8.57)$, berry width $(15.79 \mathrm{~mm})$, berry length $(22.71 \mathrm{~mm})$ and berry weight $(3.50 \mathrm{~g})$ parameters were obtained from 80-100 ppm GA3+20 ppm Forchlorfenuron application which was determined as the third application.
\end{abstract}

Keywords: GA3, Forchlorfenuron, Sultani Cekirdeksiz, Grape yield, Grape quality.

\section{Giriş}

FAO'nun 2018 yılı verilerine göre, en fazla üzüm üretimi yaklaşık 13.5 milyon ton ile Çin'de yapılmakta, İtalya, ABD, İspanya ve Fransa ise Çin'in hemen ardından üretimin yoğun yapıldığı ülkeleri oluşturmaktadır. Bağcılık dünya genelinde olduğu gibi ülkemizde de oldukça geniş alanlarda yapılmaktadır. Ülkemiz, üretim yapılan toplam 417
041 ha bağ alanı ile dünyada 5., toplam üretilen 3933000 ton üzüm miktarı ile dünyada 6. sırada yer almaktadır (FAO, 2019). Bu miktarın 1945262 tonu sofralık, 1524091 tonu kurutmalık ve 463 647 tonu ise şaraplık üzüm olarak değerlendirilmektedir.

Ülkemiz içinde en büyük üzüm üreticisi iller Manisa, Denizli ve Mersin olarak sıralanmaktadır (TÜiK, 2019). 2017 yılında dünya genelindeki üzüm verimi ortalama $9503 \mathrm{~kg} / \mathrm{ha}$ iken, ülkemizde bu 
miktar yaklaşık 10074 kg/ha olarak gerçekleşmiş olup, üretim miktarı olarak ilk sırada yer alan Çin'de ise üzüm verimi $16946 \mathrm{~kg} / \mathrm{ha}$ 'dır (FAO, 2019). Ülkemizde nispeten düşük verim alınmasının birçok sebebi bulunmakla birlikte, bunların başında ülkemizde genelde kurak şartlar altında bağcılık yapılması gelmektedir. Sofralık üretimin büyük bir kısmı, çekirdeksiz kurutmalık üretimin ise tamamına yakını Ege Bölgesi'nde yapılmakta ve Sultani Çekirdeksiz üzüm çeşidi ülkemizde en fazla yetiştirilen üzüm çeşitlerinin başında gelmektedir. Sultani Çekirdeksiz üzüm çeşidi Ege Bölgesi'nde başlıca Manisa, Denizli ve İzmir illerinde yaygın olarak yetiştirilmektedir. Çeşidin kuru üzüm üretiminin \%80-90'lık kısmı ihraç edilmekte ve bu sayede ülkemize önemli miktarda döviz kazandırılmaktadır.

Sultani Çekirdeksiz üzüm çeşidi, embriyo kesesi döllenmeye uygun ancak rudimenter çekirdekli tane oluşturan 'stenospermokarpik meyve tutumu' mekanizmasına sahiptir. Bu tane tutumu Yuvarlak Çekirdeksiz, Siyah Çekirdeksiz, Pembe Çekirdeksiz, Monukka ve Perlette üzüm çeşitlerinde de görülmektedir (Ağaoğlu, 1999).

$\mathrm{Bu}$ tane tutum mekanizmasında taneler Giberellin hormonu yetersizliğinden çekirdekli çeşitler kadar iri olamamaktadır. Bu çeşitlerin sofralık kalitelerini artırmak için Gibberellik asit (GA3) uygulamasına intiyaç bulunmaktadır. GA3'ün her bir çeşide etkisi farklılık göstermekte, ancak bunlardan özellikle Sultani Çekirdeksiz üzüm çeşidi GA3 uygulamalarına olumlu tepkiler vermektedir. Bu sebeple, çeşidin sofralık kalitesini artırmak için üreticiler tarafından dışarıdan verilen GA3 hormonu yaygın olarak uygulanmaktadır. Günümüzde kullanılan Gibberellin A3 Gibberellik asit (GA3) olarak adlandırılmakta olup, aktif ve ticari olarak kolay temin edilebilen bir Giberellin formudur. Yapılan son araştırmalara göre Gibberellinlerin günümüzde sayısı $125^{\prime}$ in üzerindedir (Taiz ve Zeiger, 2008). Genel olarak bağcılıkta GA3 partenokarpik meyve oluşumunun uyarılmasında, tane tutumunun azaltılmasında, tomurcukların sürmesinin geciktirilmesinde, tanelerin irileştirilmesinde ve üzüm çekirdeklerinde çimlenmenin teşvik edilmesinde kullanılmaktadır. Sultani Çekirdeksiz üzüm çeşidinde çiçeklenme zamanı uygulanan GA3 tane tutumunu azaltırken, tane iriliğinde ise hafif bir artışa neden olmaktadır (Eriş, 1998).

Sultani Çekirdeksiz üzüm çeşidinde GA3'ün uygulama zamanı ve dozuna göre farklı etkiler görülebilmektedir. Bu etkiler salkım seyrelmesi, tane dökümü, salkım genişlemesi ve uzaması, tanede iriliği artışı ve olgunluğun gecikmesi şeklindeki etkilerdir. Çekirdeksiz üzümlerde çiçeklerin \%80'i açtığında GA3 uygulanırsa, seyreltme ve tane irileşmesi birlikte gerçekleşmektedir. Sofralık üzüm elde etmek için 15-20 ppm dozunda iki kez GA3 uygulaması önerilmekte ve GA3 kuru üzümde de 100 tane ağırığını arttırmaktadır (Kısmalı, 1979a; Kısmalı, 1979b). Sultani Çekirdeksiz üzüm çeşidinde sofralık üzüm kalitesini arttırmak için; somaklar $5-10 \mathrm{~cm}$ ve 15-20 cm olduğu dönemde 20'şer ppm'lik iki GA3 uygulaması, çiçeklenme dönemindeki (\%50-80) 20 ppm'lik tek GA3 uygulaması, taneler saçma iriliğine (4-5 mm) ulaştığında 40'ar ppm'lik iki GA3 uygulaması önerilmektedir. Bununla birlikte, çeşidin tane tutumundan sonra salkım ucu kesme ve çilkim çıkarma işlemleriyle, koruk döneminde 21 gün arayla potasyum içerikli yaprak gübresi uygulanması da tavsiye edilmektedir (Ateş ve Karabat, 2006).

Bir sitokinin olan Forchlorfenuron ise kurutmalık üzüm çeşitlerinde ve kivi yetiştiriciliğinde kullanılan ve meyve büyüklüğü, tane tutumu ile salkım ağırlığını arttıran yeni bir bitki büyüme düzenleyicisidir.

$\mathrm{Bu}$ araştırma, Sultani Çekirdeksiz üzüm çeşidinde farklı GA3 uygulamalarının (kontrol, 15-60 ppm GA3, 20-80 ppm GA3, 80-100 ppm $\mathrm{GA} 3+20 \mathrm{ppm}$ Forchlorfenuron) üzüm verim ve kalitesine etkilerinin belirlenmesi amacıyla yürütülmüştür.

\section{Materyal ve Metot}

Bu araştırma, Denizli ilinin Honaz ilçesi Kızılyer Mahallesi'nin Karadutlar Mevkii'nde bulunan, 6 da'lık $3 \mathrm{~m}$. × $2 \mathrm{~m}$. aralık ve mesafede geniş $V$ terbiye şekliyle tesis edilmiş, 41B Amerikan asma anacı üzerine aşılı Sultani Çekirdeksiz üzüm çeşidi bağlarında, 2018 yılında yürütülmüştür. Kış budamasında omcalara karışık budama uygulanmış olup, her bir omcada 7-8 adet 12-14 gözlü bayrak bırakılmıştır. Araştırmada, Sultani Çekirdeksiz üzüm çeşidinde farklı GA3 uygulamalarının (kontrol, 15-60 ppm GA3, 20-80 ppm GA3, 80-100 ppm GA3+20 ppm Forchlorfenuron) üzüm verim ve kalitesine etkilerinin belirlenmesi amaçlanmıştır. Araştırma materyali olarak Sultani Çekirdeksiz çeşidi; orta mevsimde olgunlaşan, gelişimi kuvvetli, salkımı konik şeklinde, kanatlı, normal sıklıkta, tanesi küçük, oval şekilli, tane kabuğu normal kalınlıkta olan bir üzüm çeşididir (Duru ve Gelegen, 1975). Esas olarak kurutmalık bir çeşit olmasına rağmen, bazı kültürel işlemlerle sofralık niteliği de geliştirilmektedir (Duru ve Gelegen, 1975). Bu araştırmada, kontrol dâhil olmak üzere 4 uygulama yapılmış olup, uygulamalar 10 tekerrürlü ve her tekerrürde birer omca olacak şekilde gerçekleştirilmiştir.

$\mathrm{Bu}$ araştırma kapsamında, Sultani Çekirdeksiz üzüm çeşidinde hiçbir hormon ilavesi 
bulunmayan kontrol uygulamasıyla birlikte, 22 Mayıs ve 28 Mayıs 2018 tarihlerinde birinci, ikinci ve üçüncü uygulamalarda farklı hormon dozları tatbik edilmiştir. 22 Mayıs ve 28 Mayıs 2018 tarihlerinde sırasıyla birinci uygulamada $15 \mathrm{ppm}$ ve 60 ppm GA3, ikinci uygulamada 20 ppm ve 80 ppm
GA3 ve üçüncü uygulamada ise $80 \mathrm{ppm}$ ve 100 ppm GA3 ile buna ilaveten 4 Haziran 2018 tarihinde 20 ppm Forchlorfenuron etken maddeli büyüme düzenleyicisi uygulaması gerçekleştirilmiştir (Çizelge 1).

Çizelge 1. Sultani Çekirdeksiz üzüm çeşidinde gerçekleştirilen uygulamaların dönem ve dozları.

\begin{tabular}{lccc}
\hline \multicolumn{1}{c}{ Uygulamalar } & 22 Mayıs 2018 & 28 Mayıs 2018 & 4 Haziran 2018 \\
\hline Kontrol & 0.0 & 0.0 & 0.0 \\
Birinci uygulama & $15 \mathrm{ppm} \mathrm{GA}$ & $60 \mathrm{ppm} \mathrm{GA}$ & 0.0 \\
ikinci uygulama & $20 \mathrm{ppm} \mathrm{GA}$ & $80 \mathrm{ppm} \mathrm{GA}$ & 0.0 \\
Üçüncü uygulama & $80 \mathrm{ppm} \mathrm{GA}$ & $100 \mathrm{ppm} \mathrm{GA}$ & $20 \mathrm{ppm}$ Forchlorfenuron \\
\hline
\end{tabular}

Farklı dozlardaki GA3 uygulamaları yeni tutmuş olan tanelere 22 Mayıs 2018 tarihinde ve ince koruk döneminde (taneler 2-3 mm) iken 28 Mayıs 2018 tarihinde yapılmıştır. Farklı dozlardaki GA3 uygulamaları kollu ilaçlama pompası ile püskürtülerek gerçekleştirilmiştir. 12 Eylül 2018 tarihine kadar bütün uygulamalarda standart bakım ve sulamaların ardından, bütün uygulamaların hasadı söz konusu tarihte aynı gün içerisinde yapılmıştır. Farklı GA3 dozları ayarlanırken, 10 litrelik kabın içerisine 1 tablet GA3 konulmak suretiyle 100 ppm'lik stok çözelti elde edilmiştir. 15 ppm GA3 uygulaması; 10 litrelik stok çözeltiden 1.5 litre alınıp 8.5 litre saf su ilave edilerek hazırlanmıştır. 20 ppm GA3 uygulaması; 10 litrelik stok çözeltiden 2 litre alınıp 8 litre saf su ilave edilerek hazırlanmıştır. $60 \mathrm{ppm}$ GA3 uygulaması; 10 litrelik stok çözeltiden 6 litre alınıp 4 litre saf su ilave edilerek hazırlanmıştır. 80 ppm GA3 uygulaması; 10 litrelik stok çözeltiden 8 litre alınıp 2 litre saf su ilave edilerek hazırlanmıştır. 100 ppm GA3 uygulaması; 10 litrelik çözeltinin tamamı omcalara uygulanmıştır.

Hasat edilen bütün salkımlar (12 Eylül 2018) Çanakkale Onsekiz Mart Üniversitesi Ziraat Fakültesi Bahçe Bitkileri Bölümü Pomoloji Laboratuvarı'na getirilerek ortalama verim (kg/omca), salkım eni $(\mathrm{cm})$, salkım boyu $(\mathrm{cm})$, salkım ağırlığı (g/salkım), salkım sıklığı (1-9), salkım sayısı (adet/omca), tane eni $(\mathrm{mm})$, tane boyu $(\mathrm{mm})$, tane ağırlığı (g), L, Hue ve Chroma değerleri ile \%SÇKM, $\mathrm{pH}, \%$ asitlik ve olgunluk indisi
(\%SÇKM/\%asitlik) parametreleri incelenmiştir. Araştırmadan elde edilen veriler $\mathrm{SAS}^{\circledR}$ ver. 9 istatistik paket programı yardımıyla varyans analizine tabi tutularak, Asgari Önemli Fark (LSD) çoklu karşılaştırma testiyle $\mathrm{p}<0.05$ düzeyinde değerlendirilmiştir.

\section{Bulgular ve Tartışma}

Denizli ilinin Honaz İlçesi'nde Sultani Çekirdeksiz üzüm çeşidi üzerinde 2018 yılında yürütülen bu araştırmadan elde edilmiş olan bulgular Çizelge 2., Çizelge 3., Çizelge 4., Çizelge 5. ve Çizelge 6.'da sunulmuştur.

Sultani Çekirdeksiz üzüm çeşidinde ortalama verim (49.32 kg/omca), salkım eni $(9.59 \mathrm{~cm}$ ) ve salkım boyu $(31.97 \mathrm{~cm})$ parametrelerinde en yüksek değerler üçüncü uygulama olan 80 ppm ve 100 ppm GA3 uygulamaları+20 ppm Forchlorfenuron etken maddeli büyüme düzenleyicisi uygulamasından elde edilmiştir. Buna karşın en düşük ortalama verim değeri birinci uygulamadan $(28.90 \mathrm{~kg} /$ omca) alınmış, ikinci uygulama (33.60 kg/omca) ile hiçbir hormon ve büyüme düzenleyici uygulanmamış olan kontrol (35.95) arada farklı grupları oluşturmuştur. En düşük salkım eni ve salkım boyu kontrolde $(8.01 \mathrm{~cm}$ ve $30.45 \mathrm{~cm}$ ) belirlenirken, ikinci ve üçüncü uygulamalar arada başka grupları teşkil etmiştir (Çizelge 2).

Çizelge 2. Sultani Çekirdeksiz üzüm çeşidinde ortalama verim ile salkıma ait bazı özellikler.

\begin{tabular}{lccc}
\hline \multicolumn{1}{c}{ Uygulamalar } & $\begin{array}{c}\text { Ortalama verim } \\
\text { (kg/omca) }\end{array}$ & $\begin{array}{c}\text { Salkım eni } \\
\text { (cm) }\end{array}$ & $\begin{array}{c}\text { Salkım boyu } \\
\text { (cm) }\end{array}$ \\
\hline Kontrol & $35.95 \mathrm{~b}$ & $8.01 \mathrm{c}$ & $30.45 \mathrm{c}$ \\
Birinci uygulama & $28.90 \mathrm{c}$ & $9.14 \mathrm{~b}$ & $31.24 \mathrm{~b}$ \\
İkinci uygulama & $33.60 \mathrm{bc}$ & $9.22 \mathrm{~b}$ & $31.48 \mathrm{~b}$ \\
Üçüncü uygulama & $49.32 \mathrm{a}$ & $9.59 \mathrm{a}$ & $31.97 \mathrm{a}$ \\
\hline \multicolumn{1}{c}{ LSD (0.05) } & 4.8395 & 0.1957 & 0.2455 \\
\hline
\end{tabular}


Kontrol: Hiçbir hormon ve büyüme düzenleyici uygulanmamış. Birinci uygulama: $15 \mathrm{ppm}$ ve $60 \mathrm{ppm} \mathrm{GA}_{3}$

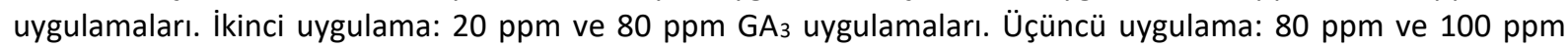
$\mathrm{GA}_{3}$ uygulamaları+20 ppm Forchlorfenuron etken maddeli büyüme düzenleyicisi uygulaması.

Çizelge 3. Sultani Çekirdeksiz üzüm çeşidinde salkıma ait bazı özellikler.

\begin{tabular}{lccc}
\hline \multicolumn{1}{c}{ Uygulamalar } & $\begin{array}{c}\text { Salkım ağırlı̆ı } \\
\text { (g/salkım) }\end{array}$ & $\begin{array}{c}\text { Salkım sıklı̆̆ } \\
\text { (1-9) }\end{array}$ & $\begin{array}{c}\text { Salkım sayısı } \\
\text { (adet/omca) }\end{array}$ \\
\hline Kontrol & $903.4 \mathrm{c}$ & $6.99 \mathrm{~d}$ & 29.30 \\
Birinci uygulama & $1087.4 \mathrm{~b}$ & $7.67 \mathrm{~b}$ & 31.50 \\
Ikinci uygulama & $1069.6 \mathrm{~b}$ & $7.57 \mathrm{c}$ & 28.40 \\
Üçüncü uygulama & $1804.3 \mathrm{a}$ & $8.57 \mathrm{a}$ & 31.70 \\
\hline \multicolumn{1}{c}{ LSD (0.05) } & 37.550 & 0.0934 & ÖD \\
\hline
\end{tabular}

ÖD: Önemli değil. Kontrol: Hiçbir hormon ve büyüme düzenleyici uygulanmamış. Birinci uygulama: 15 ppm ve

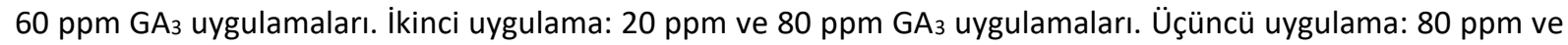
100 ppm GA $\mathrm{A}_{3}$ uygulamaları+20 ppm Forchlorfenuron etken maddeli büyüme düzenleyicisi uygulaması.

Sultani Çekirdeksiz üzüm çeşidinde salkım ağırlığı (1804.3 g/salkım) ve salkım sıklığı (8.57) parametrelerinde en yüksek değerler üçüncü uygulamadan, en düşük değerler ise kontrolden (903.4 g/salkım ve 6.99) elde edilmiştir. Birinci uygulama (1087.4 g/salkım) ve ikinci uygulamadaki (1069.6 g/salkım) salkım ağırlıkları arada farklı bir grupta yer almıştır. Salkım sıklığı birinci uygulama (7.67) ile ikinci uygulamada (7.57) arada farklı iki grubu oluşturmuştur. Salkım sayısı parametresinde ise uygulamalar arasında herhangi önemli bir farklılık tespit edilememiştir (Çizelge 3).

Sultani Çekirdeksiz üzüm çeşidinde tane eni (15.79 mm), tane boyu (22.71 mm) ve tane ağırlığı $(3.50 \mathrm{~g})$ parametrelerinde en yüksek değerler üçüncü uygulamadan, en düşük değerler ise kontrolden (12.41 mm, $16.75 \mathrm{~mm}$ ve $1.99 \mathrm{~g}$ ) alınmıştır. Birinci ve ikinci uygulamalar tane eni, tane boyu ve tane ağırlığını kontrole kıyasla arttırmış ve arada farklı grupları oluşturmuştur (Çizelge 4).

Çizelge 4. Sultani Çekirdeksiz üzüm çeşidinde taneye ait bazı özellikler.

\begin{tabular}{lccc}
\multicolumn{1}{c}{ Uygulamalar } & Tane eni $(\mathbf{m m})$ & Tane boyu $(\mathbf{m m})$ & Tane ağırlığı (g) \\
\hline Kontrol & $12.41 \mathrm{~d}$ & $16.75 \mathrm{~d}$ & $1.99 \mathrm{c}$ \\
Birinci uygulama & $15.04 \mathrm{~b}$ & $20.59 \mathrm{~b}$ & $2.96 \mathrm{~b}$ \\
İkinci uygulama & $13.52 \mathrm{c}$ & $18.10 \mathrm{c}$ & $2.66 \mathrm{~b}$ \\
Üçüncü uygulama & $15.79 \mathrm{a}$ & $22.71 \mathrm{a}$ & $3.50 \mathrm{a}$ \\
\hline \multicolumn{1}{c}{ LSD (0.05) } & 0.5938 & 0.7610 & 0.3274 \\
\hline
\end{tabular}

Kontrol: Hiçbir hormon ve büyüme düzenleyici uygulanmamış. Birinci uygulama: $15 \mathrm{ppm}$ ve $60 \mathrm{ppm} \mathrm{GA}_{3}$

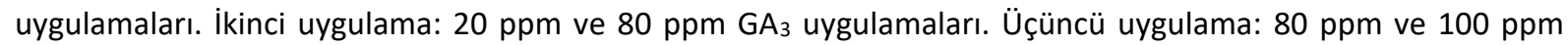
$\mathrm{GA}_{3}$ uygulamaları+20 ppm Forchlorfenuron etken maddeli büyüme düzenleyicisi uygulaması.

Çizelge 5. Sultani Çekirdeksiz üzüm çeşidinde tane rengine ait özellikler.

\begin{tabular}{lccc}
\hline \multicolumn{1}{c}{ Uygulama } & L & Hue & Chroma \\
\hline Kontrol & $36.95 \mathrm{ab}$ & $106.41 \mathrm{c}$ & $16.64 \mathrm{a}$ \\
Birinci uygulama & $32.92 \mathrm{c}$ & $112.27 \mathrm{~b}$ & $14.97 \mathrm{~b}$ \\
İkinci uygulama & $37.99 \mathrm{a}$ & $113.57 \mathrm{~b}$ & $15.33 \mathrm{~b}$ \\
Üçüncü uygulama & $35.99 \mathrm{~b}$ & $115.26 \mathrm{a}$ & $14.95 \mathrm{~b}$ \\
\hline \multicolumn{1}{c}{ LSD (0.05) } & 2.000 & 1.6562 & 1.1075 \\
\hline
\end{tabular}

Kontrol: Hiçbir hormon ve büyüme düzenleyici uygulanmamış. Birinci uygulama: 15 ppm ve $60 \mathrm{ppm} \mathrm{GA}_{3}$

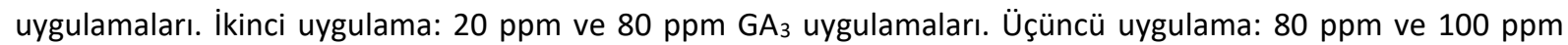
$\mathrm{GA}_{3}$ uygulamaları+20 ppm Forchlorfenuron etken maddeli büyüme düzenleyicisi uygulaması.

Sultani Çekirdeksiz ve Yuvarlak Çekirdeksiz üzüm çeşitleri üzerinde gerçekleştirilen GA3 uygulamasının tane iriliğini artırdığı, farklı araştırıcılar tarafından da belirtilmektedir (Öztürk, 1991; Butler ve Rush, 1994; Ateş ve Karabat, 2006). GA3 uygulamalarının artışıyla doza bağı olarak tane ağırlığında da artışlar meydana gelmiştir. Ilgın ve ark. (2005), Sultani Çekirdeksiz üzüm çeşidinin tane iriliğinin GA3 uygulamaları sonucunda ancak 5.50 g'a kadar çıkartılabileceğini bildirmişlerdir. Elde edilmiş olan tane ağırlığı değerlerinin nispeten düşük olmasının, araştırmada sulama sıklığının yetersizliğinden kaynaklanmış olabileceği düşünülmektedir. 
Sultani Çekirdeksiz üzüm çeşidinde ikinci uygulamadan elde edilen üzüm tanelerinde rengin daha parlak, üçüncü uygulamadan elde edilen üzüm tanelerinde yeşil rengin daha baskın, kontroldeki üzüm tanelerinde ise sarımsı yeşil rengin daha hâkim olduğu saptanmıştır. Bu nedenle kontrolde, tane renginin canlılığını ifade eden Chroma değerinin de daha yüksek olduğu belirlenmiştir (Çizelge 5).

Sultani Çekirdeksiz üzüm çeşidinde en yüksek \%SÇKM miktarı kontrolden (\%21.82) elde edilmiş, en düşük \%SÇKM miktarı ise aynı grubu oluşturan sırasıyla birinci uygulama (\%18.24), ikinci uygulama (\%18.47) ve üçüncü uygulamadan (\%18.65) alınmıştır (Çizelge 6). Araştırıcılar, GA3 uygulamalarının ben düşme ve hasat tarihlerini geciktirdiğini belirtmişlerdir (Karagözoğlu ve ark., 1981; Çelik, 1982; Öztürk, 1991). GA3 uygulamalarında \%SÇKM'nin kontrole kıyasla daha düşük olduğu yönündeki bulgularımız, araştırıcıların bu yöndeki bulgularıyla uyum içerisindedir.

Çizelge 6. Sultani Çekirdeksiz üzüm çeşidinde taneye ait kimyasal özellikler.

\begin{tabular}{lcccc}
\multicolumn{1}{c}{ Uygulama } & \%SÇKM & pH & \%asitlik & $\begin{array}{c}\text { Olgunluk indisi } \\
\text { (\%SÇKM/\%asitlik) }\end{array}$ \\
\hline Kontrol & $21.82 \mathrm{a}$ & $3.51 \mathrm{ab}$ & $0.616 \mathrm{a}$ & 35.92 \\
Birinci uygulama & $18.24 \mathrm{~b}$ & $3.38 \mathrm{~b}$ & $0.495 \mathrm{~b}$ & 36.92 \\
İkinci uygulama & $18.47 \mathrm{~b}$ & $3.59 \mathrm{a}$ & $0.509 \mathrm{~b}$ & 36.41 \\
Üçüncü uygulama & $18.65 \mathrm{~b}$ & $3.46 \mathrm{ab}$ & $0.535 \mathrm{~b}$ & 35.38 \\
\hline \multicolumn{1}{c}{ LSD (0.05) } & 0.7727 & 0.1789 & 0.0504 & ÖD \\
\hline
\end{tabular}

ÖD: Önemli değil. Kontrol: Hiçbir hormon ve büyüme düzenleyici uygulanmamış. Birinci uygulama: $15 \mathrm{ppm}$ ve 60 ppm GA $\mathrm{A}_{3}$ uygulamaları. İkinci uygulama: 20 ppm ve 80 ppm GA $\mathrm{GA}_{3}$ uygulamaları. Üçüncü uygulama: 80 ppm ve 100 ppm $\mathrm{GA}_{3}$ uygulamaları + 20 ppm Forchlorfenuron etken maddeli büyüme düzenleyicisi uygulaması.

Sultani Çekirdeksiz üzüm çeşidinde \%asitlik kontrolde en yüksek değeri (\%0.616) verirken, sırasıyla birinci uygulama (\%0.495), ikinci uygulama (\%0.509) ve üçüncü uygulamadan $(\% 0.535)$ daha düşük değerler elde edildiği görülmektedir (Çizelge 6). Bu nedenle uygulamalar bazında \%35-37 düzeylerinde bir olgunluk indisi meydana gelmiş, olgunluk indisi (\%SÇKM/\%asitlik) üzerine farklı GA 3 uygulamalarının etkisi önem oluşturmamıştır.

\section{Sonuç ve Öneriler}

Sultani Çekirdeksiz üzüm çeşidinde ortalama verim, salkım eni, salkım boyu, salkım ağılığı, salkım sıklığı, tane eni, tane boyu ve tane ağırlığı parametrelerinde en yüksek değerler üçüncü uygulama olan $80 \mathrm{ppm}$ ve $100 \mathrm{ppm}$ GA3 uygulamaları+20 ppm Forchlorfenuron etken maddeli büyüme düzenleyicisi uygulamasından elde edilmiştir. Sultani Çekirdeksiz üzüm çeşidinde üçüncü uygulamadan elde edilen üzüm tanelerinde yeşil rengin daha baskın olduğu saptanmış, kontroldeki tanelerde ise sarımsı renk hâkimiyetinden dolayı tane renginin canlılığını ifade eden Chroma değerinin daha yüksek olduğu belirlenmiştir. \%SÇKM kontrolde GA3 uygulamalarına kıyasla daha yüksek olmuş ancak, kontroldeki \%asitliğin de yüksek bulunmasıyla olgunluk indisinde (\%SÇKM/\%asitlik) herhangi önemli bir farklılık meydana gelmemiştir.

Araştırma sonucunda, Denizli ilinde 22 Mayıs ve 28 Mayıs 2018 tarihlerinde Sultani Çekirdeksiz üzüm çeşidinde yapılan 80 ppm ve 100 ppm GA3 uygulamaları + 20 ppm Forchlorfenuron etken maddeli büyüme düzenleyicisi uygulaması, kontrol ve diğer GA3 uygulamalarına kıyasla daha olumlu sonuçlar vererek önerilebilir bulunmuştur.

Yapılmış olan bu farklı uygulamaların, Sultani Çekirdeksiz üzüm çeşidi yetiştiriciliği yapılmakta olan diğer yörelerimizde de denenmesinin yararlı olabileceği düşünülmektedir.

Çıkar Çatışması Beyanı: Makale yazarları olarak aramızda herhangi bir çıkar çatışması yoktur.

\section{Araştırmacıların Katkı Oranı Beyan}

Özeti: Makale yazarları makaleye eşit oranda katkı sağlamışlardır.

\section{Kaynaklar}

Ağaoğlu, Y.S., 1999. Bilimsel ve Uygulamalı Bağcılık (Cilt I Asma Biyolojisi). Kavaklıdere Eğitim Yayınları No: 1. 205 s. Ankara.

Ateş, F., Karabat, S., 2006. Sofralık üzüm üretiminde yaşanan sorunlar ve Sultani Çekirdeksiz üzüm çeşidinde kaliteyi arttırmaya yönelik uygulamalar. 967-975. Buldan Sempozyumu. 23-24 Kasım, Buldan/Denizli.

Butler, M.D., Rush, R.E., 1994. Gibberellic Acid on sizing of Thompson Seedless table grapes in southwest Arizona. Hortscience 29. 546 p.

Çelik, S., 1982. Bitkisel hormonların bağcılıkta kullanılması. Tarım Orman ve Köy işleri 
Bakanlığı Ziraat İşleri Genel Müdürlüğü. Bağcılık Semineri. Yalova.

Duru, R., Gelegen, K., 1975. Standart Üzüm Çeşitleri. Gıda Tarım ve Hayvancılık Bakanlığı Ziraat İşleri Genel Müdürlüğü Yayınları. D-163. Ankara.

Eriş, A., 1998. Bahçe Bitkileri Fizyolojisi. Uludağ Üniversitesi Ziraat Fakültesi Ders Notları, No: 11. IV. Baskı, Bursa. $152 \mathrm{s.}$

FAO, 2019. Food and Agriculture Organization of the United Nations. http://www.fao. org/faostat/en/data. (Erişim tarihi: 24 Mart 2019).

Ilgın, C., Ateş, F., Karabat, S., Yıldız, S., Yağcı, S., 2005. Sultani Çekirdeksiz üzüm tiplerinde bazı uygulamaların sofralık üzüm kalitesi üzerine etkileri. VI. Bağcılık Sempozyumu. 179-185. Tekirdağ.

Karagözoğlu, E., Köylü, M.E., Özel, T., 1981. Gibberellik Asit uygulanmış çekirdeksiz üzümlerden elde edilen kuru üzümlerin bazı kalite özellikleri üzerinde araştırmalar. Proje Sonuç Raporu. Manisa.

Kısmalı, İ., 1979a. Çekirdeksiz üzüm çeşitlerinde meyve kalitesini arttırmak amacıyla Gibberellik Asit uygulamaları. Bitki. 6 (1): 34-37.

Kısmalı, ì., 1979b. Üzümlerde meyve kalitesini arttırıcı teknik önlemler. Ege Üniv. Ziraat Fakültesi Dergisi. 16 (3): 149-163.

Öztürk, A., 1991. Yuvarlak Çekirdeksiz üzümde GA3 ve kimi yaprak gübrelerinin yaprak besin maddeleri, ürün ve kalite üzerindeki etkileri. Ege Üniv. Fen Bilimleri Enstitüsü. Yüksek Lisans Tezi. $83 \mathrm{~s}$. İzmir.

Taiz, L., Zeiger, E., 2008. Bitki Fizyolojisi. Üçüncü baskıdan çeviri (Çeviri Editörü: Prof. Dr. İsmail Türkan). Palme Yayıncılık. $690 \mathrm{~s}$. Ankara.

TÜik, 2019. Bitkisel üretim verileri. http://www.tuik.gov.tr/. (Erişim tarihi: 25 Mart 2019). 